\title{
THE ROLE OF URODYNAMIC STUDY IN EVALUATION OF PATIENTS WITH REFRACTORY MONOSYMPTOMATIC NOCTURNAL ENURESIS
} \author{
Youssof $^{(3)}$, Islam Ali Elsiad Ahmed ${ }^{(4)}$ \\ (1)Professor and Head of urology Department,Fayoum University \\ (2)Assistant professor of urology,Fayoum University \\ (3)Lecturer of urology,Fayoum University \\ (4)Department of urology
}

Hamdy Mohmed Ibrahim ${ }^{(1)}$, Hussein Abdel-Hameed Aldaqadossi ${ }^{(2)}$, Hamada Ahmad

Corresponding author: Islam Ali Elsiad Ahmed

E-mail: islam.zon35@gmail.com

Tel: 01002428767

\begin{abstract}
:
The monosymptomatic nocturnal enuresis (MNE) is recommended by the International Children's Continence Society (ICCS) to distinguish MNE from non-monosymptomatic nocturnal enuresis (NMNE), which is accompanied by lower urinary tract symptoms (LUTS) such as daytime urinary frequency, urgency, or urinary incontinence. In general, indications for urodynamic studies (UDS) in children include the following: neurogenic bladder, sphincter dysfunction, anorectal malformations, voiding dysfunction including urge syndrome and underactive bladder, vesicoureteral reflux, urinary incontinence,
\end{abstract}

\begin{abstract}
infravesical obstruction, or obstructive uropathy. This study aimed to evaluate the role of UDS in management of refractory monosymptomatic nocturnal enuresis. This prospective study was carried out in Urology Department, Fayoum University Hospital from December 2017 to August 2018. Thirty patients with refractory MNE were enrolled in the study. The included patients with MNE were treated with mono pharmacotherapy (desmopressin) for at least six months without response. Our results show no statistically significant correlation between normal and abnormal filling cystometry.
\end{abstract}

KEY WORDS: Monosymptomatic nocturnal enuresis (MNE), urodynamic studies (UDS), detrusor overactivity (DO).

\section{INTRODUCTION:}

Nocturnal enuresis (NE) is defined as intermittent incontinence of urine, or bedwetting during sleep, in children more than 5 years of age. (1). It is a condition that includes a spectrum of disorders with different underlying pathophysiological mechanisms.(1,2) Available evidence suggests that the major undarlying factors for NE are nocturnal polyuria, small bladder capacity, detrusor overactivity and a high arousal threshold.(1-3)_UDS evaluations in NE management are unclear and controversial. Some investigators, have demonstrated the usefulness of urodynamic evaluation in children with severe NMNE or therapyresistant NE, and have suggested UDS 
evaluations for children that require extra care. $(4,5)$ It was thought that patients with a diagnosis of MNE had normal bladder function. Thus, invasive UDS was not generally performed in children in order to manage MNE. However, several studies have revealed an important role of the reduced

\section{AIM OF STUDY:}

This study aimed to evaluate the role of UDS in management of refractory monosymptomatic nocturnal enuresis (MNE).

\section{MATERIALS AND METHODS:}

A total of 30 refractory monosymptomatic nocturnal enuretic patients (16 boys and 14 girls) with a mean age of 11.83 years (range 8 to 18) were studied. The mean number of bed wetting in patients' group was 15.96 with SD \pm 2.33 and ranged from $12-28$ bed wetting

\section{RESUTS:}

The filling cystometry of 30 RMNE was normal in 13 patients (43.3\%) and abnormal in 17 patients $(56.6 \%)$ in the form of $\{$ detrusor

\section{DISCUSSION:}

Based on the results of our study, a routine UDS should not be recommended prior to a combination treatment; the combination therapy of anticholinergics with desmopressin could be applied as a first-line treatment for patients with RMNE. Similar to our study, Sehgal et al, (2007), recommended that the monosymptomatic primary enuretics with normal voiding chart may be started on behavioral therapy without subjecting them to urodynamic test. Even in polysymptomatic enuretics, drug therapy may be started empirically. Urodynamic testing may be reserved for polysymptomatic enuretics who show abnormal ultrasound or who fail to functional bladder capacity and bladder dysfunction in the progression of refractory MNE. $(4,6)$ Therefore, this study sought to determine whether or not a UDS is beneficial for NE management in pediatric patients, especially in cases of pharmacoresistant MNE (PRMNE).

nights per month. Urodynamic studies, including filling cystometry, a postvoid residual (PVR) volume of urine, uroflowmetry, all patients' had prior failed desmopressin therapy.

overactivity (DO) in 12 patients (40\%) and low bladder compliance in 5 patients $(16.6 \%)\}$, with $\mathrm{p}$-value $(>0.05)$.

respond to first line treatment. While Yucel et al, (2004), reported that the primary nocturnal enuresis (PNE) and NE persisting into adulthood may be associated with abnormal urodynamic findings. Patients may benefit from urodynamic studies, because if the findings are abnormal, they might have the best chance of successful treatment. Also, Ryu et al, (2013), reported that the urodynamic findings were helpful for selecting further treatment strategies for children with RMNE, although in the same study, it was recommend that the urodynamic studies of children with NMNE should not be performed as a routine diagnostic procedure. 


\section{CONCLUSIONS:}

The urodynamic studies in patients with refractory MNE should not be performed as a routine diagnostic procedure. Also it is recommended that a combination therapy of anticholinergics with desmopressin could be

\section{REFERENCES:}

[1]Yeung CK. Nocturnal enuresis (bedwetting). Curr Opin

Urol2003; 13: 337-43.

[2] Hjalmas K, Arnold T, Bower W et al. Nocturnal enuresis:an international evidence based management strategy.

J Urol2004; 171: 2545-61.

[3]Dehoorne JL, Walle CV, Vansintjan P et al. Characteristics of a tertiary center enuresis population, with special emphasison the relation among nocturnal diuresis, functional bladder capacity and desmopressin response. J Urol 2007; 177:1130-7.

[4]Yeung CK, Sit FK, To LK et al. Reduction in nocturnal functional bladder capacity is a applied for patients with refractory monosymptomatic nocturnal enuresis. A UDS could then be performed in patients who do not respond to the combination treatment.

common factor in the pathogenesis of refractory nocturnal enuresis. BJU Int 2002; 90:302-7.

[5]Elmissiry M, Abdelkarim A, Badawy H, Elsalmy S, Ali GA.Refractory enuresis in children and adolescents: how canurodynamics affect management and what is the optimumtest?

J Pediatr Urol 2013; 9: 348-52.

[6] Yeung CK, Chiu HN, Sit FK. Bladder dysfunction in children with refractory monosymptomatic primary nocturnal enuresis.

J Urol 1999; 162: 1049-54; discussion 54-55. 